\title{
GESTÃO DA INFORMAÇÃO: ANÁLISE BIBLIOMÉTRICA DOS TRABALHOS DE CONCLUSÃO DE CURSO DE BIBLIOTECONOMIA DA UFF E UFRJ
}

\author{
INFORMATION MANAGEMENT: BIBLIOMÉTRICA \\ ANALYSIS OF THE UNDERGRADUATE THESIS ON \\ LIBRARY SCIENCE AND DOCUMENTATION OF UFF \\ AND UFRJ
}

Luana Quintal de Souza ${ }^{1}$

Michely Mamede Jabala Vogel ${ }^{2}$

\begin{abstract}
RESUMO
Introdução: No atual ambiente tecnológico e globalizado, com a informação sendo compartilhada em tempo real, surge a necessidade de realizar atividades e processos que possibilitem gerenciar de forma eficaz o fluxo informacional. Ao identificar essa necessidade, as organizações buscam investir em recursos humanos. O Bibliotecário, como profissional da informação, tem a capacidade de trabalhar com o ciclo de vida da informação de maneira eficiente, proporcionando vantagem para as organizações em que atua. Objetivo: Busca identificar os Trabalhos de Conclusão de Curso de Biblioteconomia e Documentação da Universidade Federal Fluminense e da Universidade Federal do Rio de Janeiro, para levantar o estudo do tema Gestão da Informação na graduação. Metodologia: Empregou-se a pesquisa bibliográfica para estabelecer o referencial teórico e a Bibliometria para a mensuração da produção, realizando a pesquisa nos catálogos e repositórios das instituições escolhidas e organizou os dados em planilha, a fim de elaborar gráficos e quadros que identifiquem a cronologia da produção, qual instituição produziu mais sobre o tema, o uso de palavras-chave utilizados pelo autor comparados aos termos utilizados no processamento técnico para identificar os assuntos, e análise das referências mais utilizadas pelos alunos. Resultados: Ao todo foram analisados nove trabalhos, defendidos entre o ano de 2004 e 2014, os quais utilizaram ao todo 339 referências, 251 autores, com uma variação de 12 tipos documentais e foi identificado o uso ade 27 palavras-chave e 24 assuntos. Conclusão: Concluiu-se que ainda são poucas as

${ }^{1}$ Graduanda de Biblioteconomia da Universidade Federal Fluminense (UFF). Formada em Marketing pela Universidade Estácio de Sá. E-mail: luanaqs@id.uff.br

2 Doutora em Ciência da Informação pela Universidade de São Paulo. Professora nos cursos de Biblioteconomia e Arquivologia e no Programa de Pós-Graduação em Ciência da Informação da Universidade Federal Fluminense (UFF). E-mail: michelyvogel@gmail.com
\end{abstract}


pesquisas sobre o tema na graduação de biblioteconomia, porém acredita-se na relevância do tema por ser uma das atuações do Bibliotecário.

Descritores: Gestão da Informação. Gestão Estratégica da Informação. Trabalho de Conclusão de Curso. Biblioteconomia - UFF. Biblioteconomia - UFRJ.

\section{INTRODUÇÃO}

As organizações, frente às inovações tecnológicas e da grande produção de conteúdo, precisam otimizar o tempo e aperfeiçoar a qualidade de recuperação da informação, gerando conhecimento como ferramenta estratégica e competitiva. Esse cenário reforça a importância da Gestão da Informação (Gl) como atividade imprescindível às organizações.

Ferreira (2003, p. 42) afirma que,

[...] nas organizações, em geral, os sistemas de gestão de informação têm por finalidade fornecer informações relevantes para os tomadores de decisão e, por isso, sua principal função é a de coletar, processar e disseminar informação, isto é, filtrar a informação.

A informação é compartilhada em diferentes suportes e por distintos veículos de comunicação, o que dificulta seu tratamento e organização. Nesse contexto, a Gestão da Informação tem como função realizar a coleta, tratamento, organização, recuperação e disseminação da informação, proporcionando diversas vantagens para o desenvolvimento institucional. Starec, Gomes e Chaves (2005, p. 48) afirmam que "[...] na era da informação e da sociedade interativa e interligada em tempo real na qual vivemos, a informação é o principal ativo na luta pela sobrevivência das organizações."

A Gestão da Informação proporciona subsídios para tomada de decisão, além de permitir melhor desenvolvimento das atividades gerenciais. Silva e Vitorino (2016, p. 245) declaram que "[...] do intuito de planejamento e acompanhamento, do crescente volume de informação à disposição, aliados ao desejo de controle, emerge, nas organizações, a necessidade da Gestão da Informação." Nesse processo, a informação, quando tratada adequadamente, também pode agregar valor ao negócio, Siqueira $(2005$, p. 63) afirma 
[...] no caso do tratamento da informação, agregar valor ao negócio significa suportar, da melhor forma possível, o processo de tomada de decisão com informações de qualidade. Além disso, a informação agrega valor quando permite à empresa perceber oportunidades e ameaças a sua operação, detectando problemas e tendências.

É possível encontrar na literatura diversos autores que abordam sobre as principais etapas e atividades que envolvem a Gestão da Informação, bem como seus objetivos e funções. Com base em Beal (2004), Oliveira e Bertucci (2003), entende-se que para a Gestão da Informação seja realizada com êxito, faz-se necessário estabelecer um conjunto de diretrizes que possibilitem 0 acesso à informação relevante, precisa e com qualidade. Siqueira (2005, p. 31) considera uma das principais funções da Gestão da Informação:

[...] a ação sistêmica de procurar entender as necessidades informacionais de uma organização e disponibilizá-las para solução de problemas organizacionais, de forma estruturada e clara, com conhecimento pleno de todos os procedimentos e processos da solução encontrada, garantindo assim que ela seja eficaz e repetível.

Oliveira e Bertucci (2003, p. 76) apresentam os objetivos da Gestão da Informação como: (a) promoção da eficiência organizacional de forma a organizar e suprir as demandas por informação vindas de dentro e de fora; (b) planejamento de políticas de informação; (c) desenvolvimento e manutenção de sistemas e serviços de informação; (d) otimização de fluxos de informação e (e) controle da tecnologia de informação.

Choo (1995, p. 5) declara que "[...] o objetivo básico da gestão da informação é a de aproveitar os recursos de informação e a capacidade de informação organizacional a fim de permitir que a organização aprenda a se adaptar ao seu ambiente em constante mudança." De maneira a complementar, Duarte, Silva e Costa (2007, p. 99) destacam que "[...] a Gl tem o objetivo de garantir que a informação seja gerenciada como um recurso indispensável e valioso e que esteja alinhada com a missão e os objetivos do serviço de informação."

Para a realização do gerenciamento da informação é fundamental que a organização disponha de recursos tecnológicos e de pessoal qualificado, além 
de uma política informacional alinhada aos objetivos da organização. Conforme salientam Souza, Dias e Nassif (2011, p. 59),

[...] a gestão da informação, especificamente, envolve os estudos e as práticas gerenciais que permitem a construção, a disseminação e o uso da informação. Esse processo engloba a gestão de recursos informacionais e de conteúdos, a gestão de tecnologias da informação e a gestão das pessoas envolvidas nesses sub-processos.

Silva e Tomaél (2007) entendem que, além das pessoas, para que a Gestão da Informação se cumpra, é necessário que diferentes recursos da informação sejam mobilizados, sendo eles: tecnologia da informação, fontes, serviços e sistemas de informação. "Portanto, a Gl adere-se não apenas aos processos de organização da informação, mas também às necessidades de informação; centra-se nos fluxos e ações referentes à informação, e não somente nos sistemas de informação" (SILVA; TOMÁEL, 2007, p. 2).

Ainda sobre os diferentes aspectos e recursos envolvidos na $\mathrm{Gl}$, somente o investimento em novas tecnologias não é suficiente, conforme afirma Danvenport (1998, p. 12)

Os administradores precisam, na verdade, de uma perspectiva holística, que possa assimilar alterações repentinas no mundo dos negócios e adaptar-se às sempre mutantes realidades sociais. Essa nova abordagem, que chamo de ecologia da informação, enfatiza o ambiente da informação em sua totalidade, levando em conta os valores e as crenças empresariais sobre informação (cultura); como as pessoas realmente usam a informação e o que fazem com ela (comportamento e processos de trabalho); as armadilhas que podem interferir no intercâmbio de informações (política); e quais sistemas de informação já estão instalados apropriadamente.

A partir dos conceitos apresentados, compreende-se que o papel da Gestão da Informação, como área que gerencia o ciclo da informação permitindo o melhor desempenho de uma organização, torna-se imperativo.

Considerando que a Gestão da Informação agrega valor para as organizações, por fornecer condições competitivas, destaca-se que o estudo dessa gestão se torna inerente as diferentes áreas do conhecimento. Silva e Vitorino (2016, p. 244) reiteram que a "Gestão da Informação refere-se às atividades relacionadas à informação, fazendo intersecção com as áreas de 
Ciência da Informação, Sistemas de Informação, Tecnologia da Informação e Gestão do Conhecimento."

A Ciência da Informação "dedica-se tanto ao estudo das propriedades gerais e das condições da informação quanto aos processos que possibilitam seu processamento, sua disponibilização e seu uso efetivo." (SOUZA; DIAS; NASSIF, 2011, p. 59). No contexto das organizações e instituições, tal gestão mostra-se necessária para alcançar a eficiência dos serviços oferecidos. Seguindo essa premissa, Siqueira (2005, p. 1) afirma que "a gestão orientada ao conhecimento visa proporcionar um ambiente no qual se possa identificar, compartilhar e criar conhecimento que agregará valor à empresa e contribuirá para o alcance de suas metas e objetivos."

Ao identificar a necessidade de gerenciar os recursos informacionais de maneira eficaz, as organizações buscam investir em recursos humanos. Essa busca por mão de obra qualificada faz com que as empresas identifiquem os profissionais mais aptos a realizar as atividades relacionadas ao tratamento, organização e recuperação da informação. Chiavenato (1996) afirma que "[...] o trabalhador do conhecimento não será necessariamente aquele que opera um computador ou equipamento sofisticado, mas aquele que transforma dados processados em benefício para o cliente ou para a sociedade" (CHIAVENATO, 1996, p. 90). O Bibliotecário, como profissional da informação, tem a capacidade de trabalhar com o ciclo de vida da informação de maneira eficiente, proporcionando vantagem para as organizações em que atua. De acordo com Silva e Silva (2012):

O bibliotecário é o principal profissional que atua no mercado de trabalho dentro das bibliotecas, centros de informação, instituições de ensino, centros de documentação e empresas públicas e privadas que, além da função de agente produtor e mediador de conteúdos informacionais, desempenha também a função de gestor informacional.

Segundo Arruda, Marteleto e Souza (2000, apud PIZZARRO; DAVOCK, 2008), os Bibliotecários, enquanto profissionais da informação, estão sendo instados a reafirmar sua importância e seu valor para o mundo do trabalho em meio à transição para um novo modelo de qualificação profissional. O mercado precisa de profissionais polivalentes, que dominem o universo tecnológico e 
que sejam capazes, não só de organizar, mas principalmente de gerenciar o acervo informacional.

Souza (2004, p. 101) identifica o papel do Bibliotecário como "[...] conhecer e utilizar os meios que levam a localização de qualquer fonte de informação cujo conteúdo possa a qualquer momento ser pedido por qualquer pessoa."

Ao entender as competências que lhe foram atribuídas, fica evidente para o Bibliotecário que ele tem capacidade e habilidade para atuar como gestor da informação. Entende-se também que o profissional da área está apto a coletar, avaliar, processar, organizar, armazenar e disseminar as informações relevantes, sejam elas produzidas em ambiente interno ou externo. Destaca-se também, de acordo com Rezende (2002), Souza (2004) e Rexach Trujilo (2000), que há outras atividades específicas que impulsionam a atuação do profissional da informação no mercado de trabalho, no que tange às atividades de Gestão da Informação:

a) Conhecer as tecnologias de informação e utilizá-las com eficiência;

b) Conhecer os diferentes suportes informacionais e avaliar a utilização de cada um de acordo com a necessidade da organização;

c) Elaborar um sistema de recuperação da informação que seja de fácil entendimento ao usuário, permitindo uma recuperação relevante da informação;

d) Estruturar, junto ao corpo funcional, maneiras adequadas de conservação e preservação da informação em diferentes suportes.

Portanto, o profissional bibliotecário pode ser considerado apto para atuar na Gl e na GEl. Posto isso, passaremos à definição do papel dos Trabalhos de Conclusão de Curso na comunicação científica.

Entendendo a importância da Gl para as organizações e a relação delas com a área da Ciência da Informação, está pesquisa tem a intenção de identificar o tema nos Trabalhos de Conclusão de Curso (TCC), dos cursos de Biblioteconomia da Universidade Federal Fluminense (UFF) e Universidade Federal do Rio de Janeiro (UFRJ). A escolha pela graduação ocorre, pois acredita-se ser o início da relação e das práticas relacionadas entre o fazer técnico bibliotecário e a Gestão da Informação. 


\section{TRABALHO DE CONCLUSÃO DE CURSO COMO FONTE DE INFORMAÇÃO}

O Trabalho de Conclusão de Curso é uma monografia produzida pelo aluno para conclusão dos estudos em uma determinada área do conhecimento. Conforme salienta Monteiro (1998, p. 1), trata-se de "uma forma de complementar o processo de avaliação da aprendizagem ocorrida na sala de aula".

A NBR 14.724 (2011, p. 4) considera o Trabalho de Conclusão de Curso como um

[...] documento que apresenta o resultado de estudo, devendo expressar conhecimento do assunto escolhido, que deve ser obrigatoriamente emanado da disciplina, módulo, estudo independente, curso, programa, e outros ministrados. Deve ser feito sob a coordenação de um orientador.

Pereira e Silva (2010, p. 2) declaram que "o TCC é uma produção de conhecimento e de experiências formativas em que o aluno se relaciona com diferentes pontos de vista e com estudos realizados anteriormente sobre o seu tema de pesquisa."

Por meio dos TCC é possível verificar os passos iniciais da produção científica de uma determinada área, uma vez que expressam pensamentos acadêmicos de futuros pesquisadores e profissionais da área.

No Quadro 1, produzido por Oliveira (2003), identifica-se o processo de evolução da importância e a contribuição da monografia na formação acadêmica.

Quadro 1: As contribuições da monografia segundo a literatura

\begin{tabular}{|l|l|}
\hline \multicolumn{1}{|c|}{ Autores } & \multicolumn{1}{c|}{ Contribuições da monografia na formação } \\
\hline Belli (2000) & $\begin{array}{l}\text { Desenvolvimento de um espaço novo de construção do } \\
\text { conhecimento na formação de futuros profissionais, uma vez } \\
\text { que seu objetivo é permitir que as diferentes leituras e escritas } \\
\text { dos alunos possam se articular com as experiências já } \\
\text { vivenciadas nos estágios e/ou funções na área educacional, de } \\
\text { modo a produzir um processo individual de redefinição dos } \\
\text { valores acumulados durante a graduação. }\end{array}$ \\
\hline Eco (1983) & $\begin{array}{l}\text { Aprender a pôr ordem nas próprias ideias e ordenar os dados, } \\
\text { exercitando a memória, resgatando conceitos e experiências } \\
\text { apreendidos ao longo do curso. }\end{array}$ \\
\hline Fachim (2002) & Por ser um estudo que obedece à estrutura de um trabalho \\
\hline
\end{tabular}




\begin{tabular}{|l|l|}
\hline & $\begin{array}{l}\text { científico, propicia ao graduando a possibilidade de elaborar um } \\
\text { trabalho mais aprofundado. }\end{array}$ \\
\hline $\begin{array}{l}\text { Inácio Filho } \\
\text { (1995) }\end{array}$ & $\begin{array}{l}\text { Possibilita o levantamento de dados em fontes específicas do } \\
\text { conhecimento, ao mesmo tempo em que os dados coletados } \\
\text { vão sendo intercalados por críticas e guiados pela relevância e } \\
\text { preocupação que o pesquisador confere ao assunto, mostrando } \\
\text { sua criticidade. }\end{array}$ \\
\hline $\begin{array}{l}\text { Kerscher e } \\
\text { Kerscher (1999) }\end{array}$ & $\begin{array}{l}\text { Contribui para desenvolver o hábito de pesquisa, o sentido } \\
\text { crítico, a capacidade de análise, o poder de síntese e a } \\
\text { criatividade no campo profissional. Contribui também para } \\
\text { colher subsídios sobre assuntos técnico - profissionais. }\end{array}$ \\
\hline $\begin{array}{l}\text { Victoriano e } \\
\text { Garcia (1996) }\end{array}$ & $\begin{array}{l}\text { Serve sobretudo para ensinar a coordenar idéias. E pressupõe } \\
\text { a seguinte sequência: 1) determinação do tema-problema do } \\
\text { trabalho (dúvida, questão, problema); 2) levantamento da } \\
\text { bibliografia referente a esse tema (fontes); 3) leitura e } \\
\text { documentação (tratamento da bibliografia); 4) reflexão crítica; 5) } \\
\text { construção lógica do trabalho e 6) redação do texto } \\
\text { (monografia). }\end{array}$ \\
\hline Severino (1996) & $\begin{array}{l}\text { Sistematiza o resultado das leituras, observações, críticas e } \\
\text { reflexões feitas pelo educando. }\end{array}$ \\
\hline
\end{tabular}

Fonte: Oliveira (2003)

O TCC é uma fonte de informação de estudo e pesquisa, além de ser considerado uma fonte de informação primária. Conforme afirma Grogan (1970 apud CUNHA, 2001) "as fontes primárias contêm novas informações ou novas interpretações de ideias e/ou fatos acontecidos. São exemplos: artigos de periódicos, teses, dissertações, relatórios técnicos, patentes, dentre outros"

Colaborando com este pensamento, Pizzani et al. (2012) explica que as fontes primárias "contêm os trabalhos originais com conhecimento original e publicado pela primeira vez pelos autores. São as teses universitárias, livros, relatórios técnicos, artigos em revistas científicas, anais de congressos" (PIZZANI et al., 2012, p. 57).

Atualmente, a maioria das universidades incentiva a divulgação das monografias produzidas na instituição, apesar de não serem publicadas comercialmente. É possível recuperar os trabalhos, que muitas vezes estão acessíveis na internet ou nas bibliotecas das instituições de origem. Assim, o TCC pode ser acessado como fonte de informação e pode ser utilizado para estimular novas pesquisas e para aperfeiçoar outras já existentes.

Considerado produção científica do aluno, o Trabalho de Conclusão de Curso - compreendido como produção científica - reflete o conhecimento 
adquirido pelo aluno durante toda a graduação, bem como o processo do aluno enquanto pesquisador. Essa afirmação é consolidada ao entendermos a finalidade do ensino superior como a de:

[...] estimular a criação cultural e o desenvolvimento do espírito científico e do pensamento reflexivo, formar diplomados nas diferentes áreas do conhecimento, aptos para a inserção em setores profissionais e para participação do desenvolvimento da sociedade brasileira e colaborar na sua formação continuada, incentivar o trabalho de pesquisa e investigação cientifica, visando o desenvolvimento da ciência e da tecnologia da criação e difusão da cultura [...] (SOUZA; SILVA,1997).

$\mathrm{Na}$ comunicação científica, as pesquisas realizadas e os estudos apresentados no Trabalho de Conclusão de Curso podem ser vistos em congressos, seminários e eventos da área, pois em muitos casos os alunos levam seus trabalhos à diante, melhorando e aperfeiçoando a pesquisa e, posteriormente, apresentando-a a comunidade científica. Segundo Targino (2000, p. 10) a comunicação científica:

[...] é indispensável à atividade científica, pois permite somar os esforços individuais dos membros das comunidades científicas. Eles trocam continuamente informações com seus pares, emitindo-as para os seus sucessores e/ou adquirindo-as de seus predecessores. É a comunicação científica que favorece ao produto (produção científica) e aos produtores (pesquisadores) a necessária visibilidade e possível credibilidade no meio social em que produto e produtores se inserem.

Para Garvey (1979), a comunicação científica é definida como a troca de informações entre membros da comunidade científica. Vale acrescentar que esta contempla atividades associadas à produção, disseminação e uso da informação, desde o momento em que o cientista concebe uma ideia para pesquisar até o momento em que os resultados da pesquisa são aceitos como constituintes do conhecimento científico. Dessa maneira, entende-se a importância dos trabalhos de conclusão de curso desenvolvidos na graduação, os quais fazem parte de produções científicas e compõem a comunicação científica da área pesquisada, incentivando os alunos a aprofundarem seus conhecimentos numa determinada área, bem como a se instrumentalizarem para atuarem no tema escolhido. 


\section{PROCEDIMENTOS METODOLÓGICOS}

Para o alcance dos objetivos foi realizada a pesquisa de natureza exploratória, que busca identificar, descobrir ou gerar hipóteses sobre alguns fenômenos ou parcelas deles (FERRER; JIMÉNEZ, 2006). Ainda sobre o caráter exploratório, Gil (2010) salienta que a pesquisa exploratória é "aquela que permite proporcionar maior familiaridade com o problema com vistas a tomá-lo mais explícito ou a construir hipóteses." Por conseguinte, a pesquisa exploratória volta-se ao foco descritivo dos dados, uma vez que objetiva documentar, determinar e desenvolver as características dos fenômenos estudados" (FERRER; JIMÉNEZ, 2006).

Para tanto, foi realizada a mensuração da produção científica por meio da Bibliometria, que é definida como o "estudo da mensuração do progresso científico e tecnológico e que consiste na avaliação quantitativa e na análise das inter-comparações da atividade, produtividade e progresso científico" (SILVIA; BIANCHI, 2001, p. 6).

Os estudos métricos têm o papel de medir a ciência, possibilitando o acompanhamento da produção científica e auxiliando no desenvolvimento de novas pesquisas. Isso porque através das métricas é possível mapear e organizar a produção, identificando as lacunas ou não de determinadas áreas. Segundo Mugnaini, Carvalho e Campanatti-Ostiz (2006, p. 316)

[...] para se entender a evolução da ciência, como forma de expressão do conhecimento humano produzido são utilizadas técnicas de medição, aplicadas em estudos métricos que são realizados para estabelecimento ou fortalecimento de indicadores que permitem traçar um perfil do mundo científico, tanto em âmbito nacional como internacional.

A importância do mapeamento da produção científica ocorre no momento em que a ciência se torna determinante para o crescimento econômico do país, tornando-se necessário monitorar e avaliar as informações coletadas. Para Gomes (2006, p. 4), "os estudos métricos da ciência retratam tanto a avaliação dos insumos como, e principalmente, a produção gerada pela comunidade científica de determinada área, nos diferentes formatos de divulgação." Esses trabalhos apontam os indicadores das tendências de 
pesquisas e as "[...] fragilidades teóricas e metodológicas dessa produção, contribuindo, assim, para ultrapassá-las” (GOMES, 2006, p. 4).

Para Figueiredo (1972, p. 27), a Bibliometria é um "[...] conjunto de leis que muito contribuíram para estabelecer as bases teóricas da Ciência, da Informação - designa o tratamento quantitativo das propriedades e do comportamento da informação registrada." Ainda segundo a autora:

[...] os estudos bibliométricos fornecem subsídios básicos de pesquisa, numa tentativa de controle da explosão da informação. Na realidade, nenhuma teoria ou lei é capaz de controlar o crescimento desordenado e descontrolado da produção bibliográfica - a "publish-or-perish" corrente que ultrapassou as fronteiras americanas; mas as leis e teorias, incluindo as bibliometricas, capacitaram os cientistas da informação a entender e a analisar a literatura científica $\mathrm{cm}$ diferentes aspectos. (FIGUEIREDO, 1972, p. 27)

Dentre os estudos realizados pela Bibliometria, a que possui grande importância é a avaliação de citação, definida por Foresti (1989, p. 2) como:

[...] a parte da bibliometria que investiga as relações entre os documentos citantes e os documentos citados considerados como unidades de análise, no todo ou em suas diversas partes: autor, título, origem geográfica, ano e idioma de publicação, etc.

Foresti (1989) declara que as citações:

[...] contribuem para o desenvolvimento da ciência, proveem o necessário reconhecimento de um cientista por seus colegas, estabelecem os direitos de propriedade e prioridade da contribuição científica de um autor, constituem importantes fontes de informação, ajudam a julgar os hábitos de uso da informação e mostram a literatura que é indispensável para o trabalho dos cientistas (FORESTI, 1989, p. 2).

A análise de citações se origina no século XVII e tem, inicialmente, a função de permitir a relação entre dois documentos. Tal análise foi utilizada a primeira vez em 1927, por P. Gross e E. Gross; posteriormente, foi utilizada por Allan em 1929 e, por Gross e Woodford, em 1931. A partir da década de 60, por meio do uso de computadores, a análise de citações ganha um grande marco através do surgimento do primeiro índice de citações, o Science Citation Index (SCl), criado por Eugene Garfield, fundador do Institute of Scientific Information - ISI. 
Nota-se como a Bibliometria, através de seus instrumentos e estudos, é capaz de realizar um mapeamento da produção científica, coletando dados relevantes para a comunidade e identificando as perspectivas e comportamentos da ciência.

Quanto aos procedimentos técnicos, a pesquisa será realizada a partir da coleta e organização de dados em planilha e será representada a partir de gráficos e quadros. Realizaram-se a organização e categorização dos dados, a fim de obter uma planilha com informações suficientes que apontassem a dispersão anual de publicações por instituição, a utilização do termo nos assuntos e as palavras-chave e citações mais utilizadas, de modo a fazer ainda uma avaliação da disponibilidade nas bibliotecas institucionais dos títulos mais utilizados. Para analisar e entender os objetivos dos trabalhos recuperados, foi realizada a leitura de títulos, resumos e palavras-chave

\section{RESULTADOS E ANÁLISES DE DADOS}

A partir da pesquisa, coleta e organização dos dados, foi possível mapear a produção sobre Gestão da Informação nos Trabalhos de Conclusão de Curso de Biblioteconomia das Instituições UFF e UFRJ. 1) a UFRJ disponibiliza todos os trabalhos do curso de Biblioteconomia e Gestão de Unidades de Informação no Repositório Institucional PHANTEON, desde a primeira turma em 2010; 2) a UFF não possui nenhum trabalho com disponibilidade completa no repositório, apenas trabalhos catalogados no sistema Pergamum, o que implicou a visita à Biblioteca Central do Gragoatá para leitura do título, resumo e identificação das referências.

Dessa forma, foram obtidos nove trabalhos que utilizaram o termo Gestão da Informação no título e/ou nas palavras-chave. Foram obtidos ainda trabalhos em que o termo foi utilizado como descritor do trabalho nos catálogos e repositórios pesquisados, sendo que, quatro desses trabalhos foram defendidos na Universidade Federal do Rio de Janeiro e três na Universidade Federal Fluminense, conforme apresentado no Quadro 2. 
Quadro 2: Trabalhos recuperados

\begin{tabular}{|c|c|c|c|}
\hline Título & Autor & Instituição & Ano \\
\hline $\begin{array}{l}\text { Arquitetura de informação: pensando } \\
\text { o bibliotecário no ambiente da web }\end{array}$ & $\begin{array}{l}\text { José } \\
\text { Ferreira de } \\
\text { Lima Junior }\end{array}$ & UFF & \\
\hline $\begin{array}{l}\text { Estratégias para a gestão da } \\
\text { informação em bibliotecas }\end{array}$ & $\begin{array}{l}\text { Rejane } \\
\text { Silva de } \\
\text { Brito }\end{array}$ & UFF & \\
\hline 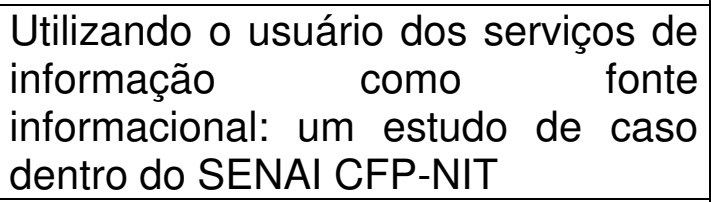 & $\begin{array}{l}\text { Marilia Dias } \\
\text { da Silva }\end{array}$ & UFF & \\
\hline $\begin{array}{l}\text { A gestão da informação como } \\
\text { requisito para evitar perdas e falhas } \\
\text { na tomada de decisão: estudo de } \\
\text { caso na empresa CONTAX }\end{array}$ & $\begin{array}{l}\text { Fabiano } \\
\text { Rodrigues } \\
\text { Salgueiro }\end{array}$ & UFF & \\
\hline $\begin{array}{l}\text { Formação educacional do Gestor da } \\
\text { Informação: uma investigação sobre } \\
\text { os cursos de graduação de Gestão } \\
\text { da Informação no Brasil }\end{array}$ & $\begin{array}{l}\text { Clarissa } \\
\text { Jurandi } \\
\text { Machado }\end{array}$ & UFRJ & \\
\hline 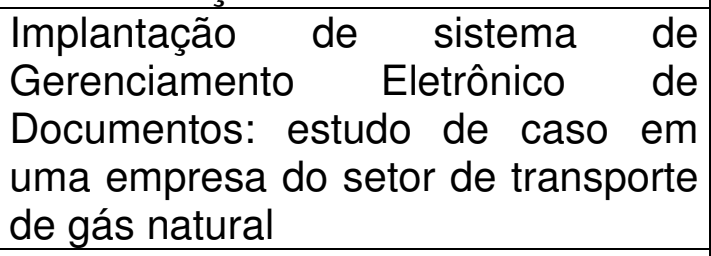 & $\begin{array}{l}\text { Igor de } \\
\text { Oliveira } \\
\text { Rodrigues } \\
\text { Dias }\end{array}$ & UFRJ & \\
\hline $\begin{array}{l}\text { O Bibliotecário utilizando } \\
\text { arquitetura da informação e a } \\
\text { usabilidade na informação esportiva }\end{array}$ & $\begin{array}{l}\text { Thiago } \\
\text { Soares de } \\
\text { Paula } \\
\text { Costa } \\
\end{array}$ & UFRJ & \\
\hline $\begin{array}{l}\text { Ferramentas da Organização } \\
\text { Conhecimento para a gestão da } \\
\text { informação e do conhecimento em } \\
\text { ambientes empresariais }\end{array}$ & $\begin{array}{l}\text { Mariana } \\
\text { Mathias } \\
\text { Moraes de } \\
\text { Oliveira } \\
\end{array}$ & UFRJ & \\
\hline $\begin{array}{l}\text { Análise das ferramentas de gestão } \\
\text { do conhecimento e da informação na } \\
\text { elaboração e execucãa de projetos }\end{array}$ & $\begin{array}{l}\text { Edilani } \\
\text { Bezerra de } \\
\text { Lima }\end{array}$ & UFRJ & \\
\hline
\end{tabular}

Fonte: Dados da pesquisa

Destaca-se que até 2010 não havia sido defendido nenhum trabalho na UFRJ, isso porque o curso foi criado em 2006 e sua primeira turma foi formada no ano de 2010. Neste ano apenas um trabalho utilizou o termo Gestão da Informação como palavra-chave. A UFF possuía desde 2004 Trabalhos de Conclusão de Curso que versavam sobre o tema, porém, após a criação do curso de Biblioteconomia e Gestão de Unidades de Informação da Universidade Federal do Rio de Janeiro, não se foi possível obter nenhum dado 
sobre os trabalhos de Gestão da Informação na Instituição. O destaque anual foi em 2013, com três trabalhos defendidos na UFRJ.

\subsection{Assuntos e Palavras-chave}

Os trabalhos apresentaram um total de 24 descritores de assunto, conforme os catálogos consultados, havendo repetição de 5 termos.

Vale ressaltar que os assuntos não são idênticos às palavras-chave apresentadas nos TCC, o que é possível entender uma vez que estas são atribuídas ao trabalho por seus autores ao passo que os assuntos são atribuídos no processamento técnico. Embora nesta pesquisa seja apresentada uma análise tanto dos assuntos como das palavras-chave, não se objetivou discutir o uso de linguagens documentárias.

O termo Gestão do Conhecimento é o que mais se repete, uma vez que a existência do termo Gestão da Informação serve de critério para a seleção de todos os trabalhos. Pode-se considerar que a relação entre a Gestão do Conhecimento e a Gestão da Informação se dá a partir do entendimento sobre a Gestão do Conhecimento, a qual se refere ao planejamento e controle de ações que governam o fluxo do conhecimento - conforme uma vertente explícita, e para isso, englobam práticas da Gestão da Informação - e sua vertente tácita (LEITE; COSTA, 2007).

Embora os três trabalhos utilizem o mesmo termo, eles não possuem outro assunto em comum, como pode ser visto no Quadro 3.

Quadro 3: Trabalhos que apresentam Gestão do Conhecimento como assunto

\begin{tabular}{|l|l|l|}
\hline TíTULO & ASSUNTO & INSTITUIÇÃO \\
\hline $\begin{array}{l}\text { Análise das ferramentas de gestão } \\
\text { do conhecimento e da informação } \\
\text { na elaboração e execução de } \\
\text { projetos }\end{array}$ & $\begin{array}{l}\text { 1- - Grojetos; } \\
\text { 2- Gestão do } \\
\text { conhecimento; } \\
\text { 3- Gestão da } \\
\text { informação; }\end{array}$ & \\
\hline $\begin{array}{l}\text { Ferramentas da Organização do } \\
\text { Conhecimento para a gestão da } \\
\text { informação e do conhecimento em } \\
\text { ambientes empresariais }\end{array}$ & $\begin{array}{l}\text { 1- Organização do } \\
\text { conhecimento; }\end{array}$ & UFRJ \\
& $\begin{array}{l}\text { 2-Gestão da } \\
\text { informação; } \\
\text { 3- Gestão do } \\
\text { conhecimento; }\end{array}$ & \\
& & \\
\hline
\end{tabular}




\begin{tabular}{|l|l|l|}
\hline & $\begin{array}{l}\text { 4- Taxonomia; } \\
\text { 5- Ontologias; } \\
\text { 6- Folksonomia; } \\
\text { 7- Mapas conceituais }\end{array}$ & \\
\hline $\begin{array}{l}\text { Utilizando o usuário dos serviços } \\
\text { de informação como fonte } \\
\text { informacional: um estudo de caso } \\
\text { dentro do SENAI CFP-NIT }\end{array}$ & $\begin{array}{l}\text { 1- Gestão do } \\
\text { conhecimento; } \\
\text { 2- Estudo de usuário; } \\
\text { 3- Gestão da } \\
\text { informação }\end{array}$ & UFF \\
\hline
\end{tabular}

Fonte: dados da pesquisa

Foi possível identificar, a partir da leitura dos assuntos, do título e do resumo, que os trabalhos não tinham como objetivo geral realizar uma revisão da literatura sobre a Gestão da Informação, mas analisar o uso e a importância da Gl para o melhor desenvolvimento das atividades e dos serviços organizacionais.

Em seguida, os termos que mais se repetiram na recuperação dos trabalhos foram: Arquitetura da Informação, Bibliotecário e Estudo de Caso, que apareceu 2 vezes. Analisa-se a seguir, no quadro 4, a utilização e a relação dos termos Arquitetura da Informação e Bibliotecário.

Quadro 4: Trabalhos que apresentam Bibliotecário e Arquitetura da Informação como assunto.

\begin{tabular}{|c|c|c|}
\hline TÍTULO & ASSUNTO & INSTITUIÇÃO \\
\hline $\begin{array}{l}\text { Arquitetura de } \\
\text { informação: pensando } \\
\text { o bibliotecário no } \\
\text { ambiente da web }\end{array}$ & $\begin{array}{l}\text { 1- Bibliotecário } \\
\text { 2- Internet } \\
\text { 3- Arquitetura da informação } \\
\text { 4- Gestão da informação }\end{array}$ & UFF \\
\hline $\begin{array}{l}\text { Estratégias para a } \\
\text { gestão da informação } \\
\text { em bibliotecas }\end{array}$ & $\begin{array}{l}\text { 1- Gestão da informação } \\
\text { 2- Biblioteca } \\
\text { 3- Bibliotecário } \\
\text { 4- Sistema de informação } \\
\text { gerencial }\end{array}$ & UFF \\
\hline $\begin{array}{l}\text { O Bibliotecário } \\
\text { utilizando a } \\
\text { arquitetura da } \\
\text { informação e a } \\
\text { usabilidade na } \\
\text { informação esportiva }\end{array}$ & $\begin{array}{l}\text { 1- Arquitetura de informação } \\
\text { 2- Indústria esportiva } \\
\text { 3- Gestão da informação } \\
\text { 4- Usabilidade } \\
\text { 5- Indústria do entretenimento } \\
\text { 6- Sociedade da informação }\end{array}$ & UFRJ \\
\hline
\end{tabular}

Fonte: dados da pesquisa 
Apesar de apenas o primeiro e o segundo trabalho apresentarem os termos Bibliotecário e Gestão da Informação simultaneamente, percebe-se, a partir da leitura do título, do assunto e do resumo, que todos os três trabalhos buscam relacionar a atuação do Bibliotecário com a utilização da Gestão da Informação - a qual funciona como um instrumento para aperfeiçoar determinado serviço ou processo, possibilitando inovações e vantagens estratégicas para a biblioteca. Isso pode ser um indicativo do interesse do aluno de graduação, do curso de biblioteconomia, pela relação da GI com a atuação do Bibliotecário.

Pode-se justificar a relação das pesquisas e a utilização dos termos Arquitetura da Informação e Gestão da Informação com base em Davenport (1988), pois o autor afirma que "o mapeamento de informações está inserido no contexto da Gestão da Informação, mais especificamente no eixo da arquitetura da informação e é focalizado na utilização da informação no presente, ou seja, aquela que se tem hoje e que é utilizada pela organização."

Percebe-se, portanto, a contribuição de diversas áreas para o desenvolvimento de atividades que envolvem a informação.

Os assuntos apresentados foram utilizados no momento do processamento técnico das bibliotecas, em que os trabalhos compõem o acervo. Esse processo envolve o catalogador, a obra e os padrões de catalogação definidos pela instituição, o que pode implicar divergência entre os termos escolhidos pelos autores e pelos catalogadores para identificar os assuntos da pesquisa.

Acerca das palavras-chave foram utilizados 27 termos no total. Observou que, entre os nove trabalhos recuperados, um não utilizou o termo Gestão da Informação como palavra-chave. Há, portanto, oito ocorrências do termo.

Assim como nos assuntos, o termo Gestão do Conhecimento é o que mais se repete, seguido dos termos Arquitetura da Informação e Informação, conforme apresentado no Quadro 5. 
Quadro 5: Trabalhos que apresentam Gestão do Conhecimento, Arquitetura da Informação e Informação como palavras-chave

\begin{tabular}{|c|c|c|}
\hline Título & Palavras-chave & Instituição \\
\hline $\begin{array}{l}\text { O Bibliotecário utilizando a } \\
\text { arquitetura da informação e a } \\
\text { usabilidade na informação } \\
\text { esportiva }\end{array}$ & $\begin{array}{l}\text { 1. Informação Esportiva } \\
\text { 2. Gestão da Informação } \\
\text { 3. Arquitetura da } \\
\text { Informação } \\
\text { 4. Usabilidade }\end{array}$ & UFRJ \\
\hline $\begin{array}{l}\text { Análise das ferramentas de } \\
\text { gestão do conhecimento e da } \\
\text { informação na elaboração e } \\
\text { execuçâo de projetos }\end{array}$ & $\begin{array}{l}\text { 1. Projetos } \\
\text { 2. Gestão do } \\
\text { conhecimento } \\
\text { 3. Gestão da informação }\end{array}$ & UFRJ \\
\hline $\begin{array}{l}\text { Ferramentas da Organização do } \\
\text { Conhecimento para a gestão da } \\
\text { informação e do conhecimento } \\
\text { em ambientes empresariais }\end{array}$ & $\begin{array}{l}\text { 1. Organização do } \\
\text { conhecimento } \\
\text { 2. Gestão da informação } \\
\text { 3. Gestão do } \\
\text { conhecimento } \\
\text { 4. Taxonomia } \\
\text { 5. Ontologia } \\
\text { 6. Folksonomia } \\
\text { 7. Mapas conceituais }\end{array}$ & UFRJ \\
\hline $\begin{array}{l}\text { Arquitetura de } \\
\text { informação: pensando o } \\
\text { bibliotecário no ambiente da web }\end{array}$ & $\begin{array}{l}\text { 1. Arquitetura da } \\
\text { informação } \\
\text { 2. Internet } \\
\text { 3. Hipertexto } \\
\text { 4. Bibliotecário }\end{array}$ & UFF \\
\hline $\begin{array}{l}\text { A gestão da informação como } \\
\text { requisito para evitar perdas e } \\
\text { falhas na tomada de decisão: } \\
\text { estudo de caso na empresa } \\
\text { CONTAX }\end{array}$ & $\begin{array}{l}\text { 1. Tomada de decisão } \\
\text { 2. Gestão da informação } \\
\text { 3. Fluxo informacional } \\
\text { 4. Informação } \\
\text { 5. Empresa Contax }\end{array}$ & UFF \\
\hline $\begin{array}{l}\text { Utilizando o usuário dos serviços } \\
\text { de informação como fonte } \\
\text { informacional: um estudo de } \\
\text { caso dentro do SENAI CFP-NIT }\end{array}$ & $\begin{array}{l}\text { 1. Gestão do } \\
\text { conhecimento } \\
\text { 2. Gestão da informação } \\
\text { 3. Informação } \\
\text { 4. Usuário } \\
\text { 5. SENAl } \\
\end{array}$ & UFF \\
\hline
\end{tabular}

Fonte: Dados da pesquisa

Verifica-se que, na disparidade entre os termos selecionados entre os autores e os catalogadores, encontra-se em destaque o termo Informação, que em nenhum momento foi utilizado no processamento técnico. Apenas o último trabalho apresentou os três termos simultaneamente. 


\subsection{Referências}

Os trabalhos apresentaram 339 referências no total e 251 autores, os dados foram organizados e analisados quanto ao tipo de documento, autores e títulos mais citados. Após essa análise, destaca-se, no Gráfico 1, os autores mais citados:

Gráfico 1: Autores mais citados

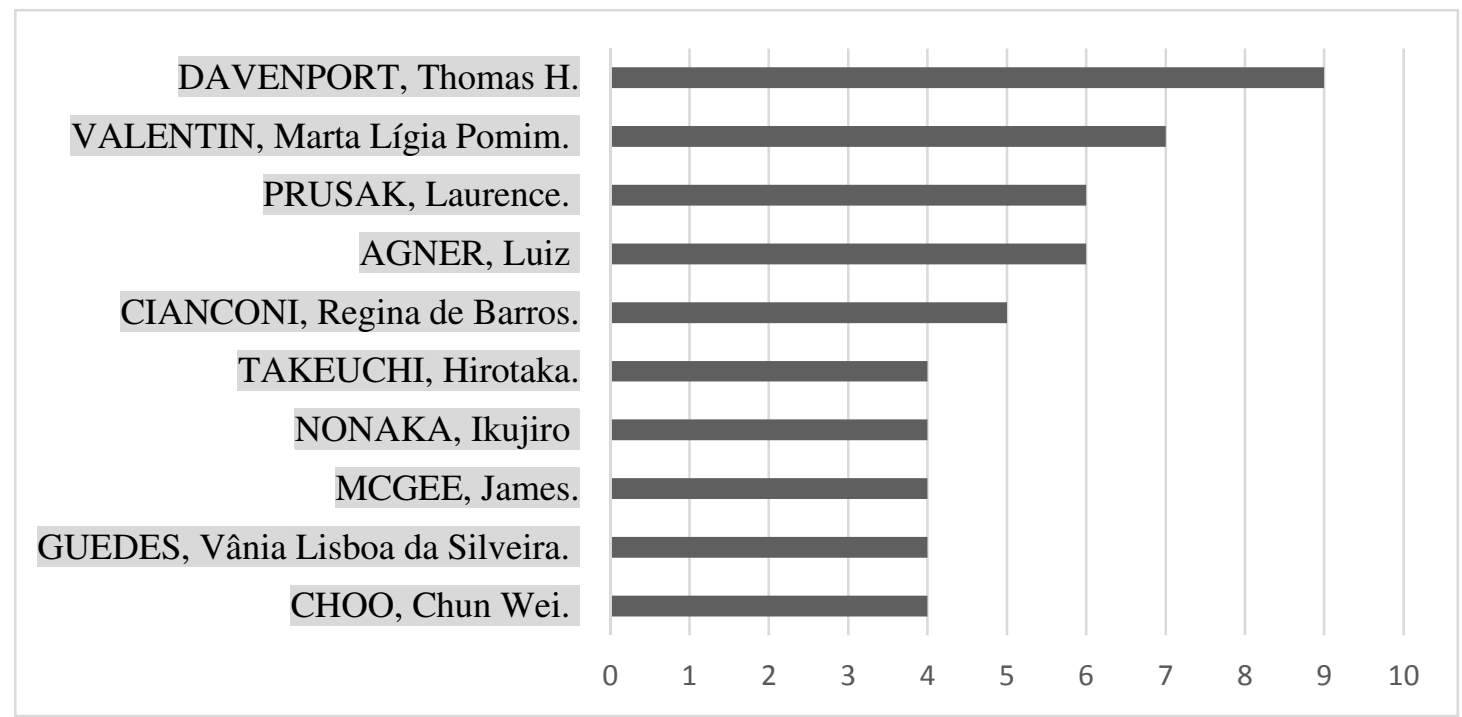

Fonte: Dados da pesquisa

O corte foi de quatro ocorrências ou mais. Salienta-se que os autores citados não foram encontrados em ambas as universidades, conforme exposto no Gráfico 2.

Gráfico 2: Número de citações por universidade

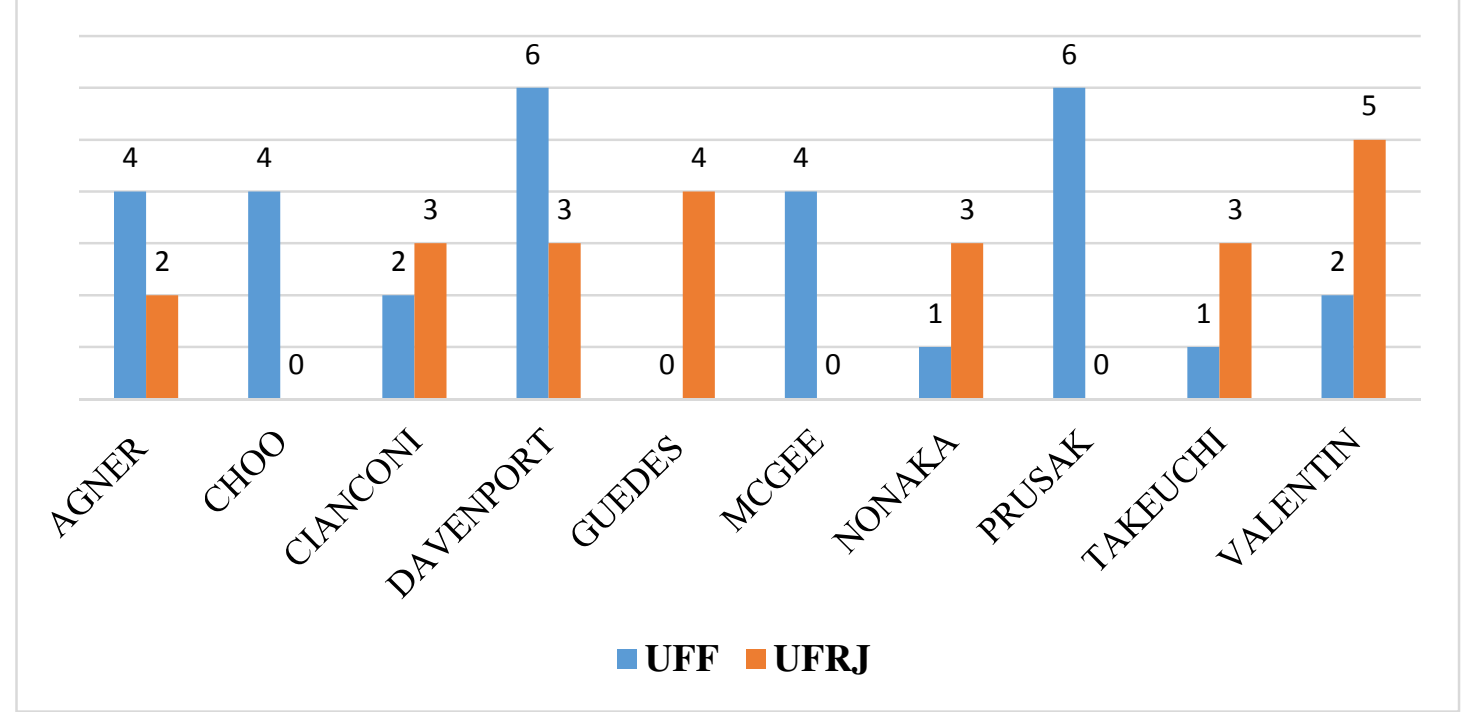

Fonte: Dados da pesquisa 
Esses autores foram utilizados em referências de livros e artigos, tendo destaque para o livro "Ecologia da Informação" de Davenport, citado cinco vezes em suas diferentes edições. Observa-se que nem todos os autores mais citados foram os mais utilizados em referências de livros, conforme evidenciado no Gráfico 3.

Gráfico 3: Relação de autores e livros mais citados

\begin{tabular}{|c|c|c|c|c|c|}
\hline & 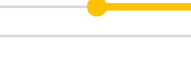 & $\rightarrow$ & & 2 & $\longrightarrow$ \\
\hline & $\begin{array}{l}\text { CHOO, Chun } \\
\text { Wei. }\end{array}$ & $\begin{array}{c}\text { Gestão da } \\
\text { informação } \\
\text { na sociedade } \\
\text { do } \\
\text { conheciment } \\
\text { o } \\
\text { CIANCONI, } \\
\text { Regina de } \\
\text { Barros. }\end{array}$ & $\begin{array}{l}\text { Ecologia da } \\
\text { Informação } \\
\\
\text { DAVENPOR } \\
\text { T, Thomas } \\
\text { H. }\end{array}$ & $\begin{array}{c}\text { Criação de } \\
\text { conheciment } \\
\text { o na empresa } \\
\\
\text { NONAKA, } \\
\text { I.; } \\
\text { TAKEUCHI, } \\
\text { H. }\end{array}$ & $\begin{array}{c}\text { Sociedade da } \\
\text { Informação } \\
\text { no Brasil: } \\
\text { livro verde. } \\
\\
\text { TAKAHASH } \\
\text { I, Tadao. }\end{array}$ \\
\hline- Total & 3 & 3 & 6 & 3 & 2 \\
\hline
\end{tabular}

Fonte: Dados da pesquisa

Diante dos resultados, surgiu o interesse em verificar se os documentos citados faziam parte do acervo das bibliotecas da UFF e UFRJ. Dessa forma, foi realizada uma pesquisa nos catálogos das bibliotecas das universidades e identificou-se o seguinte cenário: 1) os títulos "Gestão da Informação na sociedade do conhecimento" e "Sociedade da Informação no Brasil: livro verde" não foram localizados em nenhumas das bibliotecas das instituições; 2) o título "A organização do conhecimento: como as organizações usam a informação para criar significado, construir conhecimento e toma decisão" não foi localizado na UFRJ, enquanto o catálogo da UFF apresentou seis exemplares do mesmo e 3) o livro com mais exemplares disponíveis em ambas instituições, em suas diferentes bibliotecas foi "Criação de conhecimento na empresa, em suas diferentes edições". 


\subsubsection{Tipos de documentos}

Quanto aos tipos de documentos, os trabalhos apresentaram 12 tipos documentais diferentes, entre livros, artigos, dissertações e outros. As porcentagens de uso foram apresentadas no gráfico 4 a seguir:

Gráfico 4: Tipos de documentos

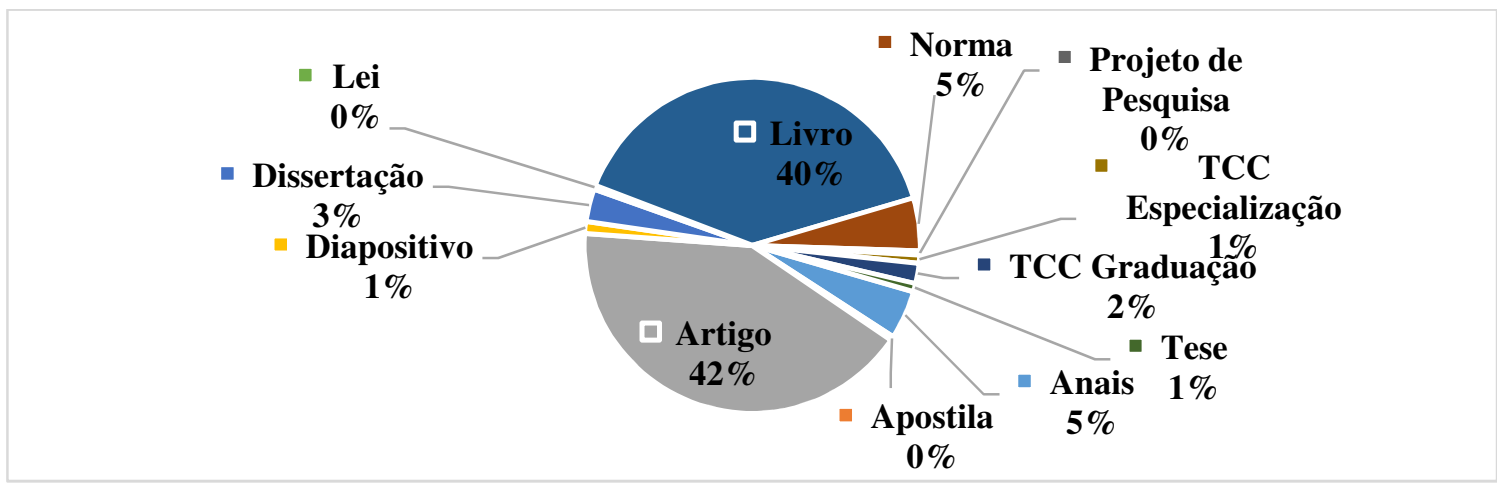

Fonte: Dados da pesquisa

Verifica-se que os artigos e livros são os tipos de documentos mais utilizados pelos alunos no momento da pesquisa, para subsidiar a construção teórica dos trabalhos.

Para uma visualização específica, no que tange às instituições, organizaram-se os dados conforme os Gráficos 5 e 6, que apresentam os tipos de documentos por instituições.

Gráfico 5: tipos de documentos utilizados nas referências dos TCC defendidos na UFRJ

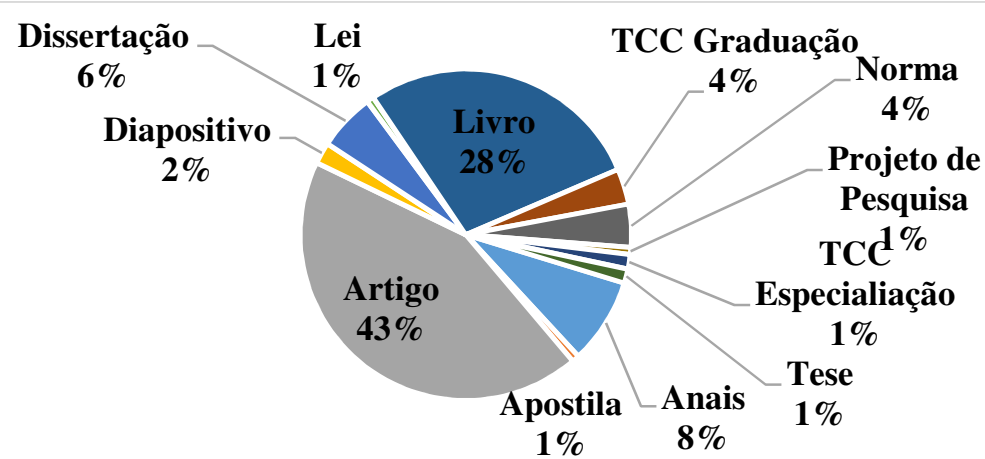

Fonte: Dados da pesquisa 
Gráfico 6: tipos de documentos utilizados nas referências dos TCC defendidos na UFRJ

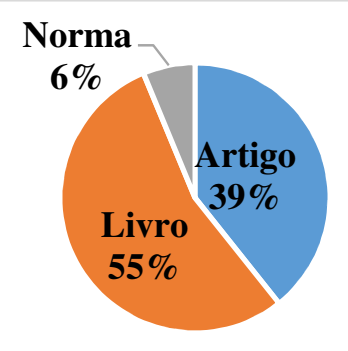

Fonte: Dados da pesquisa

Em uma análise comparativa, pode-se visualizar que a UFRJ apresenta nove tipos a mais que a UFF, além disso, na UFRJ, o número de artigos possui uma diferença de $14 \%$ quanto ao uso de livros, enquanto na UFF essa dispersão ocorre de maneira oposta e com uma diferença de apenas $4 \%$.

A partir dos resultados e das análises serão realizadas, no capítulo a seguir, as considerações finais.

\section{CONSIDERAÇÕES FINAIS}

A busca pelo termo Gestão da Informação resultou em Trabalhos de Conclusão de Curso, que foram desenvolvidos com diferentes objetivos e perspectivas. A recuperação desses trabalhos proporcionou: 1) uma análise quanto ao período de defesa dos TCC; 2) a observação quanto aos termos relacionados ao tema pesquisado, com a finalidade de identificar suas relações e 3) a identificação dos autores mais citados e dos títulos mais referenciados para construção teórica do tema.

Os dados coletados possibilitaram o cumprimento do objetivo geral e dos específicos, visto que eles apresentaram informações suficientes para a realização das análises propostas:

- $\quad$ Analisar os títulos, resumos e palavras-chave dos TCC para identificar a temática Gestão de Estratégica da Informação;

- Verificar, cronologicamente, a produção do tema nos TCC;

- Verificar qual instituição produz mais sobre o tema;

- Avaliar as referências da área. 
Observou-se a importância da escolha do título, das palavras-chave, da elaboração do resumo e da escolha das palavras-chave e dos termos selecionados no processamento técnico para identificação dos assuntos dos trabalhos, uma vez que foram esses recursos que tornaram possível a recuperação das pesquisas.

No que tange à análise das referências, na qual foi possível identificar os autores e obras mais citadas, verificou-se a presença de autores nacionais e estrangeiros, destacando a presença da autora Marta Lígia Pomim Valentim, que aparece nas buscas iniciais, em outras bases de dados e nos TCC.

A análise dos descritores, apesar de não fazer parte do objetivo desta pesquisa, permitiu identificar a dispersão entre a indexação realizada pelos autores e a realizada pelos catalogadores no momento do processamento técnico. Acredita-se que isso ocorra devido à utilização de vocabulário controlado pelas instituições, a fim de uniformizar a recuperação da informação.

Quanto aos tipos de documentos, fica claro o uso de livros e artigos em maior frequência, totalizando mais de $50 \%$ de utilização em relação aos outros.

Concluiu-se que ainda são poucas as pesquisas na graduação sobre a Gestão da Informação e Gestão Estratégica da Informação. Esse cenário pode impactar a atuação profissional do Bibliotecário na área, visto que, observa-se a falta de interesse por um tema valoroso. Conforme visto no referencial teórico, a informação se tornou o artefato de maior valor para as organizações, influenciando no desenvolvimento de qualquer instituição que queira se perpetuar.

Verifica-se que a bibliometria pode auxiliar a produção científica, isso porque ela possibilita a identificação de gaps na literatura, influenciando a evolução das pesquisas.

De modo a complementar esse estudo, sugere-se uma análise mais ampla no que diz respeito aos níveis de produção acadêmica. As análises devem contemplar as pesquisas de estudantes de mestrado e doutorado, buscando as produções de outras regiões do Brasil e, se oportuno, o mapeamento da produção internacional. Sugere-se também um acompanhamento periódico para checar a evolução das referências, 
verificando a permanência ou surgimento de novos autores e títulos mais referenciados.

\section{REFERÊNCIAS}

ASSOCIAÇÃO BRASILEIRA DE NORMAS TÉCNICAS. NBR 14724:

informação e documentação: trabalhos acadêmicos: apresentação. Rio de Janeiro, 2011.

BEAL, A. Gestão estratégica da informação: como transformar a informação e a tecnologia da informação em fatores de crescimento e de alto desempenho nas organizações. São Paulo: Atlas, 2004.

CHIAVENATO, I. Os novos paradigmas: como as mudanças estão mexendo com as empresas. São Paulo: Atlas, 1996. 319 p.

$\mathrm{CHOO}, \mathrm{C} . \mathrm{W}$. Information management for the intelligent organization: roles and implications for the information professions. In: Digital Libraries Conference. Anais.... Singapore: National Computer Board of Singapore, p. 81-99, 1995.

CUNHA, M. B. da. Para saber mais: fontes de informação em ciência e tecnologia. Brasília: Briquet de Lemos/Livros, 2001. 168 p.

DAVENPORT, T. H. Ecologia da informação: por que só a tecnologia não basta para o sucesso na era da informação. São Paulo: Futura, 1998.

DUARTE, E. N.; SILVA, A. K. A.; COSTA, S. Q. Gestão da informação e do conhecimento: práticas de empresa "excelente em gestão empresarial" extensivas à unidades de informação. Informação \& Sociedade: Estudos, João Pessoa, v. 17, n. 1, p. 97-107, jan./abr., 2007. Disponível em:

<http://www.ies.ufpb.br/ojs/index.php/ies/article/view/503>. Acesso em: 04 dez. 2017.

FERREIRA, Danielle Thiago. Profissional da informação: perfil de habilidades demandadas pelo mercado de trabalho. Ciência da Informação, Brasília, $v$. 32, n. 1, p. 42-49, jan./abr. 2003.

FIGUEIREDO, L. M. Distribuição da literatura geológica brasileira: estudo bibliométrico. 1972. 82 f. Dissertação (Mestrado em Ciência da Informação) Curso de Pós-Graduação em Ciência da Informação, Instituto Brasileiro de Bibliografia e Documentação, Universidade Federal do Rio de Janeiro, Rio de Janeiro, 1972. 
FORESTI, N. Estudo da contribuição das revistas brasileiras de biblioteconomia e ciência da informação enquanto fonte de referência para a pesquisa. 1989. 209 f. Dissertação (Mestrado em Biblioteconomia e Documentação) - Departamento de Biblioteconomia da Universidade de Brasília, UnB, Brasília, 1989.

GARVEY, W. D. Communication: the essence of science facilitating information among librarians, scientists, engineers and students. Oxford: Pergamon Press, 1979. 332 p.

GIL, A. C. Como elaborar projetos de pesquisa. 4. ed. São Paulo: Atlas, 2010. 175 p.

GOMES, M. Y. F. S. de F. Tendências atuais da produção científica em Biblioteconomia e Ciência da Informação no Brasil. DataGramaZero: Revista de Ciência da Informação, v. 7, n. 3, jun. 2006. Disponível em: <www.dgz.org.br>. Acesso em: 07 ago. 2007.

LEITE, F. C. L.; COSTA, S. M. S. Gestão do conhecimento científico: proposta de um modelo conceitual com base em processos de comunicação científica Ciência da Informação, Brasília, v. 36, n. 1, p. 92-107, jan./abr. 2007.

MELÉNDEZ FERRER, L.; PÉREZ JIMÉNEZ, C. Propuesta estructural para la construcción metodológica en investigación cualitativa como dinámica del conocimiento social. Enlace: Revista Venezolana de Información, tecnología y conocimiento, Zulia, v. 3, n. 3, p. 33-50, Sep./Dic. 2006. Disponível em < http://www.redalyc.org/articulo.oa?id=82330303>. Acesso em: 14 out. 2017.

MONTEIRO, G. Guia para elaboração de projetos, trabalhos de conclusão de curso (TCCs), dissertação e teses. São Paulo: Edicon, 1998.

MUGNAINI, R.; CARVALHO, T.; CAMPANATTI-OSTIZ, H. Indicadores de produção científica: uma discussão conceitual. In: POBLACION, D. A.; WITTER, G. P.; SILVA, J. F. M. da. Comunicação \& produção científica: contexto, indicadores e avaliação. São Paulo: Angellara, 2006. p. 313-340.

OLIVEIRA, G. A. P. de. A concepcão de egressos de um curso de Pedagogia acerca da contribuição do trabalho de conclusão de curso. 2003.136 f. Dissertação (Mestrado em Educação) Faculdade de Educação, Universidade Estadual de Campinas, Campinas, São Paulo, 2003.

OLIVEIRA, M.; BERTUCCI, M. da G. E. de S. A pequena e média empresa e a gestão da informação. Informação \& Sociedade: Estudos, João Pessoa, v. 13, n. 2, p. 65-87, jul./dez. 2003. 
PEREIRA, A. A. C.; SILVA, M. L. O. R. O trabalho de conclusão de curso: constructo epistemológico no currículo formação, valor e importância. 2010. Disponível em < http://fedathi.multimeios.ufc.br/rides/phocadownload/artigos_iiienforsup_adicion ais.pdf>. Acesso em: 04 dez. 2017.

PIZZARRO, D. C.; DAVOK, D. F. O papel do bibliotecário na gestão da informação Empresarial: uma pesquisa bibliográfica em Periódicos nacionais de biblioteconomia e ciência da informação. Revista ACB: Biblioteconomia em Santa Catarina, Florianópolis, v. 13, n. 1, p. 37-58, jan./jun., 2008.

PIZZANI, L. et al. A arte da pesquisa bibliográfica na busca do conhecimento. Revista Digital de Biblioteconomia e Ciência da Informação, Campinas, v. 10, n. 1, p. 53-66, jul./dez. 2012. Disponível em < https://periodicos.sbu.unicamp.br/ojs/index.php/rdbci/article/view/1896>. Acesso em: 04 dez. 2017.

REXACH TRUJILLO, M. E. Nuevos retos del profesional de la información a las puertas del tercer mileni. Universo Diagnóstico, v. 1, n. 1, p. 14-16, 2000. Disponível em:< http://bvs.sld.cu/revistas/uni/vol1_1_00/uni02100.htm>. Acesso em: 12 abr. 2018.

REZENDE, Y. Informação para negócios: os novos agentes do conhecimento e a gestão do capital intelectual. Ciência da Informação, Brasília, v. 31, n. 2, p. 120-128, maio/ago. 2002. Disponível em: $<$ http://www.scielo.br/scielo.php?pid=S010019652002000100008\&script=sci_abstract\&tIng=pt>. Acesso em: 12 abr. 2018.

SILVA, E. C. R.; VITORINO, E. V. A Gestão da Informação sob a abordagem da Ecologia: possibilidades à competência em informaçãa. Em Questão, Porto Alegre, v. 22, n. 1, p. 242-266, jan/abr. 2016. Disponível em: <http://seer.ufrgs.br/index.php/EmQuestao/article/view/55547>. Acesso em: 13 out. 2017.

SILVA, I. C. da.; SILVA, E. R. Atuação do bibliotecário na gestão da informação e do conhecimento em organizações pública e privada. In: Encontro Regional de Estudantes de Biblioteconomia, Documentação, Ciência E Gestão Da Informação, 15, 2012, Cariri. Anais...Cariri: UFC, 2012.

SILVA, J. A. da. BIANCHI, M. de L. P. Cientometria: a métrica da ciência.

Paidéia, Ribeirão Preto, v. 11, n. 21, p. 5-10. 2001. Disponível em: $<$ http://www.scielo.br/scielo.php?script=sci_arttext\&pid=S0103863X2001000200002>. Acesso em: 06 out. 2017.

SILVA, T. E.; TOMÁEL, M. I. A gestão da Informação nas organizações. Informação \& Informação, Londrina, v. 12, n. 2, jul./dez. 2007. Disponível em: <http://www.uel.br/revistas/uel/index.php/informacao/article/view/1806/1540>. Acesso em: 08 out. 2017. 
SIQUEIRA, M. C. Gestão estratégica da informação. Rio de Janeiro: Brasport, 2005. $158 \mathrm{p}$.

SOUZA, E. D.; DIAS, E. J. W.; NASSIF, M. E. A gestão da informação e do conhecimento na Ciência da Informação: perspectivas teóricas e práticas organizacionais. Informação \& Sociedade: Estudos, João Pessoa, v. 21, n. 1, p. 55-70, jan./abr. 2011. Disponível em:

<http://www.ies.ufpb.br/ojs/index.php/ies/a rticle/view/4039/5598>. Acesso em: 05 out. 2017.

SOUZA, F. C. O nome do profissional "bibliotecário" no Brasil: o efeito das mudanças sociais e econômicas dos últimos anos do século XX. Encontros Bibli: Revista Eletrônica de Biblioteconomia e Ciência da Informação, Florianópolis (SC), n. 18, 2004. Disponível em:< https://periodicos.ufsc.br/index.php/eb/article/view/1518-2924.2004v9n18p90 > . Acesso em: 09 abr. 2018.

SOUZA, P. N. P. de.; SILVA, E. B. da. Como entender e aplicar a nova LDB (Lei N 9.394/96). São Paulo: Pioneira, 1997.

STAREC, C.; GOMES, E. B. P.; CHAVES, J. B. L. (Org.). Gestão estratégica da Informação e Inteligência Competitiva. São Paulo: Saraiva, 2005. 351 p.

TARGINO, M. das G. Comunicação científica: uma revisão de seus elementos básicos. Informação \& Sociedade: Estudos, João Pessoa, v. 10, n. 2. 2000. Disponível em: <http://www.ies.ufpb.br/ojs/index.php/ies/article/view/326/248>. Acesso em: 02 dez. 2017.

\title{
INFORMATION MANAGEMENT: BIBLIOMÉTRICA ANALYSIS OF THE UNDERGRADUATE THESIS ON LIBRARY SCIENCE AND DOCUMENTATION OF UFF AND UFRJ
}

\begin{abstract}
Introduction: Introduction: In the current technological and globalized environment, with the information being shared in real time, the need arises to carry out activities and processes that allow to manage the information flow effectively. By identifying the need to manage information resources effectively, organizations seek to invest in human resources. The Librarian, as an information professional, has the ability to work with the information lifecycle in an efficient manner, providing an advantage to the organizations in which it operates. Objective: Identify the undergraduate thesis on Library Science and Documentation at the Fluminense Federal University and at the Federal University of Rio de Janeiro, for the accomplishment of them. Methodology: The bibliographical research was used to establish the theoretical reference and the bibliometry for the production measurement, conducting a research in the catalogs and repositories of the chosen institutions and organizing the data in spreadsheet, in order to elaborate graphs and pictures that identify the chronology of the production, which one produced more on the topic, the usage of keywords was equal to the author compared the terms used
\end{abstract}


in the processing to the identification of subjects, and the analysis of the words most used by the students. Results: This study analyzed nine theses defended between the year 2004 and 2014, which used 339 references, 251 authors, with a variance of 12 documents types and was identified the use of 27 keywords and 24 subjects. Conclusions: It was concluded that there are still few as researchers on the subject in library science, however, there is a belief that this subject is relevant because it is one of the activities of the librarian.

Descriptors: Information Management. Strategic Information Management. Undergraduate Thesis. Library Science and Documentation-UFF. Library Science and Documentation - UFRJ.

\section{GESTIÓN DE LA INFORMACIÓN: ANÁLISIS BIBLIOMÉTRICA DE LOS TRABAJOS DE CONCLUSIÓN DE CURSO DE BIBLIOTECONOMÍA DE LA UFF Y UFRJ}

RESUMEN

Introducción: En el actual entorno tecnológico y globalizado, con la información compartida en tiempo real, surge la necesidad de realizar actividades y procesos que posibiliten gestionar de forma eficaz el flujo informacional. Al identificar la necesidad de administrar los recursos informativos de manera eficaz, las organizaciones buscan invertir en recursos humanos. El Bibliotecario, como profesional de la información, tiene la capacidad de trabajar con el ciclo de vida de la información de manera eficiente, proporcionando ventaja para las organizaciones en que actúa. Objetivo: Identificar los Trabajos de Conclusión de Curso de Biblioteconomía y Documentación de la Universidad Federal Fluminense y de la Universidad Federal de Río de Janeiro, para levantar el estudio del tema Gestión de la Información en la graduación. Metodología: Se empleó la investigación bibliográfica para establecer el referencial teórico y la Bibliometría para la medición de la producción, realizando la investigación en los catálogos y repositorios de las instituciones escogidas y organizó los datos en planilla, a fin de elaborar gráficos y cuadros que identifiquen la cronología de la producción, qué institución produjo más sobre el tema, el uso de palabras clave utilizadas por el autor comparados a los términos utilizados en el procesamiento técnico para identificar los asuntos, y análisis de las referencias más utilizadas por los alumnos. Resultados: En total fueron analizados nueve trabajos, defendidos entre el año 2004 y 2014, los cuales utilizaron en total 339 referencias, 251 autores, con una variación de 12 tipos documentales y se identificó el uso ade 27 palabras clave y 24 asuntos. Conclusión: Se concluyó que todavía son pocas las investigaciones sobre el tema en la graduación de biblioteconomía, pero se cree en la relevancia del tema por ser una de las actuaciones del Bibliotecario.

Descriptores: Gestión de la Información. Gestión Estratégica de la Información. Proyecto final de curso. Biblioteconomía - UFF. Biblioteconomía - UFRJ.

Recebido: 04.03.2018

Aceito: 31.05 .2018 